\title{
AÇÕES DE ATORES TERRITORIAIS: A CONSTRUÇÃO DO PORTO DE RIO GRANDE-RS, BRASIL, COMO UM NÓ ESTRATÉGICO NO TERRITÓRIO DO SUL DO BRASIL
}

\author{
Actions of territorial actors: the construction of the Rio Grande-RS, Brazil, as an \\ strategic node in south Brazil territory
}

Ricardo Borges da Cunha*

Aldomar A. Rückert**

* Doutorando do Programa de Pós-Graduação em Geografia da UFRGS. ricardoborges85@yahoo.com.br. ** Professor no Programa de Pós-Graduação em Geografia da UFRGS. aldomar.ruckert@gmail.com

Recebido em 15/04/2019. Aceito para publicação em 20/04/2019.

Versão online publicada em 26/04/2019 (http://seer.ufrgs.br/paraonde)

\begin{abstract}
Resumo: A formação de um território passa pela ação de atores territoriais que estabelecem estratégias mediante seus objetivos e necessidades. 0 trabalho tem como finalidade reconhecer a atuações dos atores na formação e transformação das estruturas de um nó estratégico territorial, o Porto do Rio Grande, no sul do Brasil. As alterações nas relações econômicas, políticas e sociais acarretam em mudanças nas ações dos atores e refletiram na alteração das formas de uso do território. Dentro da conjuntura do porto não foi diferente, um ponto estratégico construído para delimitar a então colônia portuguesa, tornou-se porta de acesso da regional para o comércio global e foi reestruturado as necessidades de cada período e dos atores envolvidos. Dentre os atores o Estado se destaca pela mutação de suas ações, atuando em alguns períodos como um controlador das estruturas outros como um facilitador para os demais atores.
\end{abstract}

Palavras-chave: Atores territoriais; infraestrutura; Estado.

\begin{abstract}
The formation of a territory is through the action of territorial actors who establish strategies through their goals and needs. Thus, this work aims to recognize the actions of the actors in the formation and transformation of the structures of a strategic territorial node, the Seaport of the Rio Grande, in southern Brazil. The changes in economic, political and social relations lead to changes in the actions of the actors and reflected in the alteration of the forms of territorial use. Within the conjuncture of the seaport was no different, a strategic point built to delimit the then Portuguese colony, became the regional gateway to global trade and was restructured the needs of each period and the actors involved. Among the actors, the State stands out by the mutation of its actions, acting in some periods as a controller of the other structures as a facilitator for the other actors.
\end{abstract}

Key-words: Territorial actors; infrastructure; state.

\section{Introdução}

A extensa faixa litorânea brasileira ${ }^{1}$ possibilitou a instalação de amplas estruturas portuárias de norte a sul da costa. Devido ao vasto litoral, os portos são de extrema relevância para o desenvolvimento do país, funcionando como principal porta de acesso ao comércio internacional. A consolidação dos portos é diretamente ligada à formação social e econômica do Brasil e fundamental para o desenvolvimento de seu território, pois tal infraestrutura tem significativa importância em distintos períodos. (RÜCKERT, 2003)

O crescente papel dos portos levou a construção de importantes sistemas de infraestrutura terrestre (ferrovias e rodovias), responsáveis por ligar o interior do país às zonas portuárias.

${ }^{1}$ Com 7.635 km, se for levado em conta todas às reentrâncias (bacias, golfos, ...) a distância é ampliada para 8.698 km (SHERER, 2009). 
Algumas cidades possuem uma estreita relação entre o seu desenvolvimento e a localização junto à costa, devido à instalação de estruturas portuárias marítimas, como Paranaguá (PR), Vitória (ES), Santos (SP) e Rio Grande (RS). Entretanto os portos não possuem um papel exclusivo para a cidade onde estão localizados, mas assumem funções estratégicas no território, para uma região ou hinterlândia portuária.

A formação e as transformações que passam os portos marítimos são consolidadas a partir das ações de diferentes atores, os quais necessitam de tal estrutura para atingir determinados fins. As novas formas de circulação de bens e informações submeteram os territórios a novos interesses. 0 fortalecimento das relações comerciais tem nas movimentações marítimas um dos seus pilares, ao ligar distintos pontos com a circulação de grandes volumes de mercadorias, com custo e tempo reduzidos.

Com a modernização dos meios de locomoção e a dispersão industrial, novos atores territoriais, como as empresas transnacionais, assumiram um papel importante na formação das estruturas. A organização de zonas portuárias ocorreu por um conjunto de atores e suas ações que levaram a composição de estruturas com a finalidade de explorar os acessos marítimos. A construção de zonas portuárias, não ocorre exclusivamente pela localização próxima ao litoral, mas sim por um conjunto de fatores. A necessidade do escoamento de produção, a reserva de matéria prima ou a localização de mercados consumidores, foram fatores fundamentais para a construção dos portos.

0 artigo tem como objetivo compreender a participação dos atores territoriais na formação do porto do Rio Grande, destacando as transformações ocorridas a partir de novos interesses. A localização estratégica e o crescimento das relações comerciais fizeram que com esse nó estratégico, componente da rede global, fosse alvo de diferentes objetivos em períodos distintos. A atuação dos atores é responsável pela formação da estrutura e das relações desenvolvidas no porto. 0 Estado, e suas escalas, foram analisados com destaque, uma vez que o poder desse ator é singular perante os demais e o seu papel foi moldado mediante as novas formas de uso do território.

A relevância de analisar um porto ocorre em virtude da amplitude de suas conexões, elo entre as atividades produtivas e os mercados consumidores. 0 Porto do Rio Grande, único porto marítimo do estado, é fundamental para a cadeia produtiva estadual. Inicialmente o artigo aborda o papel dos atores na organização territorial, destacando a capacidade de construir estruturas para atingir os objetivos traçados. Em um segundo momento é apresentado à formação do porto e o papel dos atores nas diferentes etapas de crescimento da estrutura portuária.

\section{Desenvolvimento}

Para abordar o papel dos atores territoriais, na construção e no desenvolvimento de um nó territorial, é necessário referências teóricas para delimitar o conceito de atores. Os trabalhos de Rosière (2007) e Raffestin (1993) permitem uma definição dos mesmos e uma compreensão dos processos que envolvem esses e a transformação do território. 0 primeiro compreende ator como toda entidade que elabore representações territoriais e práticas espaciais, efetuando suas representações sobre o espaço, estruturando redes e territórios. (ROSIÈRE, 2007)

Toda prática espacial, mesmo embrionária, induzida por um sistema de ações ou de comportamentos se traduz por uma "produção territorial" que faz intervir tessituras, nós e redes (RAFFESTIN, 1993, p.150). Do Estado ao indivíduo, de complexas organizações a pequenos grupos todos são atores capazes de produzirem territorialidades, a partir de sua intencionalidade. A capacidade de transformação territorial torna os atores responsáveis por inúmeras organizações políticas, sociais e econômicas, as quais refletem e são reflexo do território.

Assim os atores são responsáveis pela formação e transformação do território e das estruturas territoriais. 0 território é utilizado por diferentes atores e as distintas relações de poder de cada período formam malhas, redes e centralidade que são flexíveis (RAFFESTIN, 1993). 0 território enquanto produto é utilizado de variadas formas e distintas funções, a formação de novas 
conjunturas econômicas e políticas acarretam em novos usos e transformações territoriais.

O espaço (isto é o território, conforme RAFFESTIN interpreta LEFEBVRE) é um instrumento político: sua representação está sempre a serviço de uma estratégia projetada (LEFEBVRE, 19 76, p. 25-31), 0 processo de construção territorial corresponde, portanto, a uma estratégia de um conjunto de atores, os quais procedem à repartição das superfícies através do desenho de uma tessitura, implantando-se nós e construindo redes. (RÜCKERT, 2003, p.26)

Os atores possuem relações diferenciadas com o território, a partir da capacidade e da intenção de cada um. 0 Estado é o ator com papel relevante, frente os demais atores, devido sua capacidade de representação territorial e sua soberania dentro de suas fronteiras. Entretanto, apesar da soberania ser pertinente a todos os Estados territoriais, a capacidade de desenvolver estruturas e ações não é encontrado igualmente entre os diferentes Estados (ROSIÈRE, 2007). Com a alteração das relações entre Estado e os demais atores, os conflitos de interesse, quando não resolvidos, podem gerar consequências similares à perda de soberania. Portanto, os Estados são os atores incontornáveis do ponto de vista territorial, mas não incontestáveis, pois a percepção desses como atores hegemônicos dentro do território, não corresponde com a complexidade das relações atuais. "O uso do território pode ser definido pela implantação de infraestruturas,..., mas também pelo dinamismo da economia e da sociedade". (SANTOS e SILVEIRA, 2001, p.20)

Porém o Estado não é o único ator com capacidade de dispor de informações e poder para modificar o território, pois tem surgido atores com significativa atuação territorial. Para Taylor e Flint (2002) o poder dentro do sistema atual de organização social, política e econômica ocorre através de uma numerosa combinação de instituições, porém o Estado segue sendo uma instituição chave. A ação conjunta é uma importante marca contemporânea e a sinergia possibilita a ampliação dos impactos das ações territoriais. "A divisão territorial do trabalho cria uma hierarquia entre lugares e redefine, a cada momento, a capacidade de agir das pessoas, das firmas e das instituições". (SANTOS e SILVEIRA, 2001, p.20)

Rosière (2007) faz uma distinção entre atores clássicos e "novos" atores. Os primeiros são: Estado, as Forças Armada e a Igreja, os quais sofrem com a competição dos "novos atores". Os partidos políticos, as guerrilhas, as ONG's (Organizações Não-Governamentais), a mídia e os atores econômicos (como empresas transnacionais), são alguns dos novos atores. Esses atores canalizam seus esforços, organizando linhas e funções (espacial e social), constroem territórios, com o poder de influenciar as ações de atores clássicos. Um exemplo é o Estado atuando sobre o território para abrir canais de comunicação e romper fronteiras, quando necessário. As empresas constroem sucursais, fragmentam mercados, rompendo barreiras que podem impedir a sua expansão ou criar melhores condições (RAFFESTIN, 1993), demonstrando seu poder. O poder no mundo moderno é operado através de uma infinidade de combinação de instituições (TAYLOR e FLINT, 2002).

A globalização das relações econômicas criou um cenário de desconcentração espacial da produção, as empresas localizam-se onde for mais conveniente, criando um fluxo que não permite fronteiras (barreiras). Liberalização que foi possível com a perda de parte da capacidade de controle dos Estados, ou seja, uma perda de soberania (FONT e RUFÍ, 2006). Entretanto essa perda de soberania, não é involuntária, pois os Estados participaram da abertura do mercado comercial e financeiro, visando principalmente não sofrerem exclusões econômicas, políticas e sociais. A construção de estruturas e políticas com a finalidade de atrair investimentos externos são estratégias construídas pelos governos para remodelarem seu território para as novas relações do sistema capitalista.

A organização da economia foi a que mais sofreu com a modernização das relações territoriais e entre os atores. As finanças romperam barreiras existentes, movimentando grandes quantias em curtos períodos, tonando-se tão fortes quanto qualquer organização estatal. Porém para que ocorresse isso os Estado tiverem que abrir a suas economias, desenvolvendo um território atrativo para o capital, privatizando empresas e dando a suas bolsas dimensões mundiais. Isso levou a uma redução da soberania estatal, porém essa não foi assumida por outros agentes, mas sim fatiada com

ParaOnde!?, Porto Alegre, v.11, n.1, p.45-54, 2019. http://seer.ufrgs.br/paraonde

Edição Especial: "Geografia e transformações socioespaciais: dinâmicas agrárias e políticas do desenvolvimento regional" 
diferentes grupos (empresas, pequenos investidores, bancos ou grande corporações), "Ou seja, o mercado financeiro mostra-se como uma combinação de agentes globais e locais, entre os quais o Estado perdeu boa parte de sua capacidade de intermediação e de decisão, mas ele continua, não obstante, a depender em grande parte deste". (FONT e RUFÍ, 2006, p. 112)

Alguns dos novos atores, não possuem uma ligação territorial, fazendo que suas estratégias sejam direcionadas a partir de seus interesses, independente do local de instalação (ROSIĖRE, 2007). Sem dúvida os atores econômicos, são os maiores expoentes dessa categoria, pois, competem sobre o território e tem no Estado um agente regulador de suas ações. Porém, a capacidade de transformação desses atores atinge até mesmo as políticas estatais, manipulando governos para estruturar espaços ou romper barreiras, para alcançar seus objetivos.

Assim as alterações nas relações entre os atores e na capacidade dos mesmos para atingir seus objetivos acarretam em mudanças territoriais que simbolizam as diferentes formas de organização da economia, da política e da sociedade. E os portos, como importantes nós estratégicos, passam por significativas transformações, a organização das relações de cada período refletem nas estruturas e no papel das zonas portuárias. Portanto a seguir será analisado a evolução das estruturas do Porto do Rio Grande a partir do papel dos atores territoriais.

\section{3. - A formação do Porto do Rio Grande e a ação dos atores territoriais}

Localizado no sul do Rio Grande do Sul, o município do Rio Grande teve a posse formal consolidada pelos portugueses em 1737 e após enfrentamento com os espanhóis, ainda no século XVIII, desenvolveu-se com base em uma estrutura portuária de significativa expressão para a província/estado. Um conjunto de investimentos estatais e privados, direcionados ao desenvolvimento portuário, deu um caráter estratégico ao município, em relação a interesses econômicos, políticos e militares. Entre as consequências está a constituição de um polo de desenvolvimento econômico, com períodos de crescimento baseados em distintos produtos e impulsionados por diferentes atores.

O município conta com o quarto maior porto marítimo em movimentação de carga do Brasil, sendo os três primeiros os portos de Santos (SP), Itaguaí (RJ) e Paranaguá (PR) em 2016. 0 porto do Rio Grande destaca-se pelo crescimento de 24,9\% no total de movimentação nos anos de 2015 e 2016. (SECRETARIA DOS PORTOS DA PRESIDENCIA DA REPÚBLICA, 2017). Entretanto, até atingir o volume de movimentação atual foi necessário um longo processo de desenvolvimento portuário. A instalação do porto criou arranjos econômicos, políticos e sociais estabelecidos pela relação dos atores envolvidos na construção da complexa estrutura territorial, composta não apenas pela composição marítima, mas também por uma extensa malha intermodais que articulam a ligação entre diferentes pontos.

A Figura 1 apresenta a localização do município do Rio Grande, destacando as estruturas portuárias formadas no município a partir das ações de distintos atores.

Para0nde!?, Porto Alegre, v.11, n.1, p.45-54, 2019. http://seer.ufrgs.br/paraonde 
Figura 1: Localização do Município do Rio Grande e sua estrutura portuária

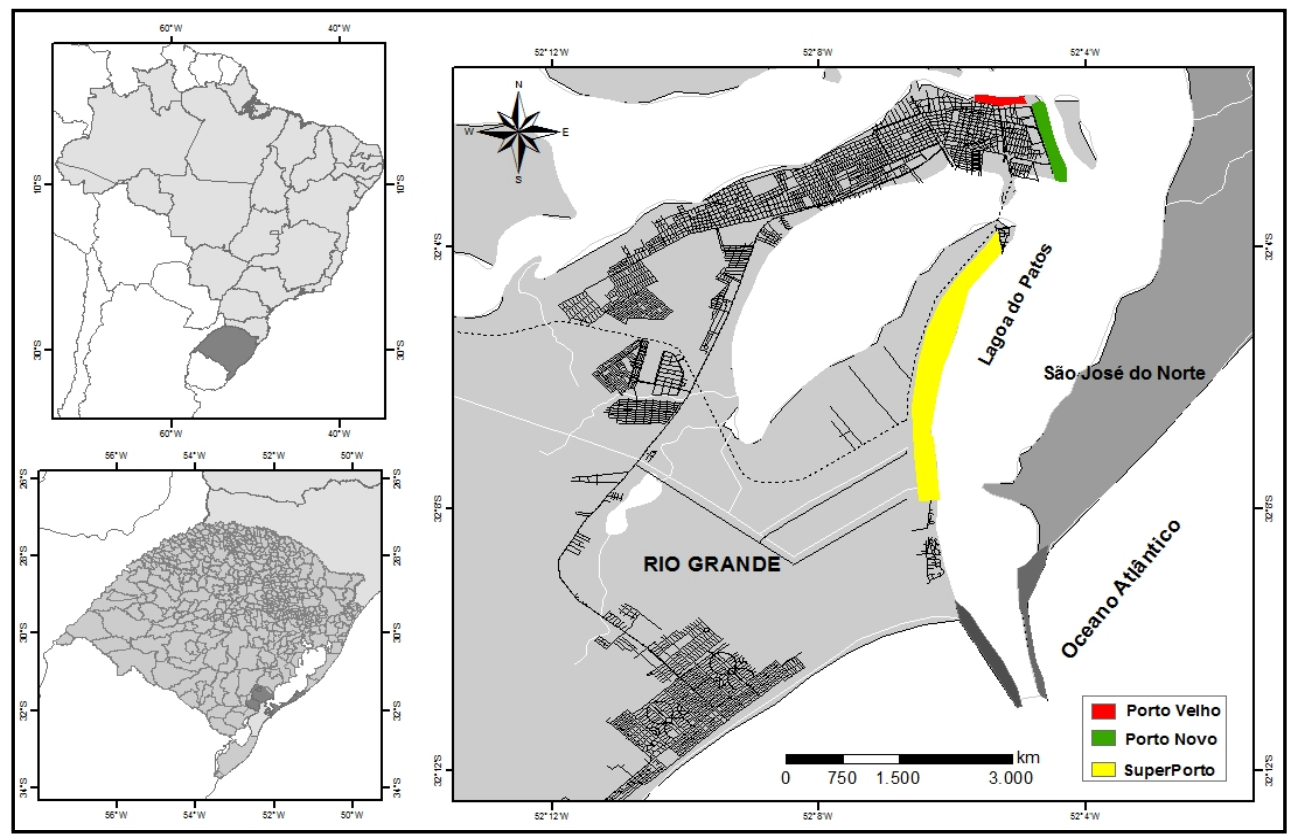

Fonte: IBGE - 2012, elaborado pelo autor.

0 processo que levou a formação do município é diretamente ligado à ocupação portuguesa na América do Sul. A localização junto ao Oceano Atlântico, na entrada da Lagoa dos Patos, acesso navegável em direção ao interior do território português, no sul da colônia, e no caminho entre a região platina e a Europa, tornou a Vila do Rio Grande São Pedro um ponto estratégico. A posição privilegiada, em relação aos interesses no sul do continente, fez com que, entre os anos de 1763 e 1776, a então vila fosse dominada pelos espanhóis, perdendo a função de capital da província. (CESAR, 2015)

Após a retomada portuguesa do controle territorial em 1776, a localização estratégica permitiu o crescimento da Vila ocorreu a partir das atividades econômicas ligadas ao porto, baseada no comércio de produtos oriundos da pecuária. Segundo Pensavanto (1985), no século XVIII o Rio Grande do Sul se tornou o principal fornecedor de charque para o mercado brasileiro e exportava o couro, para a Europa. Com a instalação de comércios e residência de negociantes na cidade de Pelotas, a fonte de charque, foi possível a expansão econômica da região baseada na exportação do produto via porto do Rio Grande. A necessidade dos comerciantes de melhores estruturas para a exportação, como o acesso seguro de navios maiores, revelava a necessidade da construção de uma melhor estrutura portuária. (RÜCKERT, 2003)

0 interesse de atores econômicos levou a busca junto à coroa portuguesa de investimentos para melhorar as condições para o comércio, principalmente na ampliação das estruturas do porto para facilitar o escoamento da produção e a entrada de mercadorias. Em 1804 foi instalada a Alfândega do Rio Grande, devido o crescimento do comércio internacional, deixando para trás a função de demarcação territorial e consolidando-se como entreposto comercial. A abertura dos portos brasileiros, a partir de 1808, permitiu novas relações comerciais com as nações amigas. (CESAR, 2015)

No início do século XIX muitos comerciantes, do Rio de Janeiros e outras localidades, instalaram filias de casas comerciais na vila do Rio Grande. A falta de estrutura para o recebimento de grandes embarcações, que dificultava o comércio, foi amenizada em 1823, com a construção do Porto Velho e a dragagem do canal de acesso, permitindo a atracação de navios com mais de 200 toneladas, dinamizando o comércio (BITTENCOURT, 2001), atendendo a demanda dos comerciantes locais e realizado com recursos do Estado. Entretanto, navios maiores continuavam com dificuldade para acessar o porto, devido ao seu canal sinuoso, dando vantagens aos portos platinos na concorrência 
com o porto gaúcho (RAMOS, 2002).

A entrada de comerciantes acabou impulsionando a relevância do porto como nó estratégico para a província e marcando a presença de atores econômicos que foram fundamentais da o pleno desenvolvimento da economia da região. 0 crescimento das relações econômicas e políticas da então vila foram fundamentais para criação, em 1835, da cidade do Rio Grande por meio de lei provincial. (TORRES, 2008). O aumento das trocas comerciais gerou uma maior atuação do Estado com a melhoria das condições portuárias e da fiscalização alfandegária.

A concorrência platina aliada a alta carga de impostos cobrados dos produtos exportados e importados levou ao descontentamento dos proprietários de estâncias e charqueadores, culminando na Revolução Farroupilha (1835 - 1845), disputa entre os revolucionários separatistas do Rio Grande do Sul contra o Império brasileiro. Durante os confrontos o controle do porto de Rio Grande foi estratégico, pois ao não conseguir controlar o porto os revolucionários tiveram sua principal fonte de renda reduzida, isto é a exportação de charque. 0 desgaste dos confrontos armados e a dificuldade de manter o comércio de charque foram fundamentais para o fim do conflito. (MARTINS, 2006)

O crescimento da movimentação portuária, para suprir a província, atraiu imigrantes voltados ao comércio internacional, sendo fundada em 1844, a Associação Comercial do Rio Grande, a primeira do estado e $4^{\mathrm{a}}$ do Brasil, que tinha como um dos seus objetivos a melhoria do canal de acesso ao porto (MARTINS, 2006). A instituição tinha entre os seus objetivos à busca por melhores condições territoriais, entre a quais o porto. A consolidação da conexão comercial local ocorre com a expansão do capitalismo comercial, ao nível mundial, e a ligação das casas comerciais, instaladas no munícipio, com centros os comerciais europeus. (SALVATORI et.al, 1989)

Em 1872 foi inaugurada a reestruturação do Porto Velho, que melhorou as condições do cais, área que foi ampliada em 1910 com a construção de armazéns (TORRES, 2008). A integração do porto com a campanha gaúcha foi consolidado com a finalização da estrada de ferro entre Rio Grande e Bagé em 1884. E consolidada com conexão das linhas ferroviárias Porto Alegre-Uruguaiana e Rio Grande-Bagé em 1905, junto da construção do Porto Novo de Rio Grande estimulam a economia do estado gaúcho. (RÜCKERT, 2003)

0 enfraquecimento do comércio de charque, ocasionado pelo avanço tecnológico ocorrido a partir da Revolução Industrial, como a refrigeração e o desenvolvimento dos meios de transporte, permitiu uma nova forma de organização territorial. Harvey (2005) coloca que as revoluções tecnológicas são processos que podem solapar a coerência estrutural dos espaços regionais, por liberaram tanto a produção quanto o consumo de espaços limitados, superando barreiras espaciais e reduzindo significativamente a variável tempo.

Contudo, à localização estratégica permitiu a instalação, no município, de um conjunto de indústrias, formando no século XIX um importante parque fabril e uma nova organização territorial. Assim, é reorganizada a estrutura produtiva local baseada no capitalismo industrial, impulsionado pelo capital acumulado com o comércio (PESAVENTO, 1985; MARTINS, 2006). Os atores econômicos, formada por donos de indústrias ${ }^{2}$ nesse período, iniciaram uma fase de reformulação do território local, orientada por investimentos estatais em infraestrutura e a atuação privada na implantação industrial.

Diferentes indústrias atuaram no parque industrial local: têxtil, beneficiamento de alimentos e bens de consumo. 0 conjunto de empresas levou o município à condição de $3^{\underline{a}}$ maior economia do país no período (MARTINS e PIMENTA, 2004). A partir de 1890 foram realizadas melhorias no setor portuário, como o aprofundamento do canal e a construção dos molhes ${ }^{3}$, como forma de solucionar o problema do acesso de navios, juntamente da construção do Porto Novo, entre 1911 e 1917, uma

\footnotetext{
${ }^{2}$ As indústrias eram em sua maioria propriedade de famílias que conseguiram recursos com a exportação de charque e couro na metade sul do Rio Grande do Sul. (CESAR, 2015)

${ }^{3}$ A construção dos molhes foi considerada a maior obra de engenharia hidráulica da América Latina, movimentando cerca de 14 mil trabalhadores e 4 bilhões de quilos de pedras para a estrutura. (TORRES, 2008 e PRADEL, 1979)
}

Para0nde!?, Porto Alegre, v.11, n.1, p.45-54, 2019. http://seer.ufrgs.br/paraonde

Edição Especial: "Geografia e transformações socioespaciais: dinâmicas agrárias e políticas do desenvolvimento regional” 
moderna estrutura para a época. As obras ficaram a cargo da Compagnie Française du Port e Barra do Rio Grande e permitiram o abastecimento de matéria-prima e o escoamento da produção industrial e ampliou de forma significativa a capacidade portuária. (MARTINS, 2006)

A estrutura portuária foi financiada através de um acordo entre o governo federal e a Compagnie Française du Port e Barra do Rio Grande, além da construção da estrutura a empresa francesa teve a concessão do governo de explorar os serviços portuários durante 20 anos, como forma de compensação dos investimentos realizados. Essa exploração durou pouco tempo, devido aos altos valores cobrados, em relação aos portos platinos, e a consequente redução da movimentação de embarcações a companhia francesa chegou a um acordo com o governo federal e o porto foi repassado ao governo estadual.

A ampliação do porto deve ser relacionada à expansão das linhas ferroviárias por todo o estado do Rio Grande do Sul, reflexo do arrendamento das estradas de ferro ao capital privado. A unificação de linhas e a sua maior extensão, somadas com o crescimento da capacidade portuária de Rio Grande serviram de estimulo para as atividades econômicas do centro sul do estado (RÜCKERT, 2001). A permissão, por parte do governo estadual, da entrada de capital estrangeiro resultou, entre os anos de 1917 e 1918, na instalação de três grandes frigoríficos no estado, sendo um deles em Rio Grande. A Cia. Swift S.A. do Brasil, uma empresa norte-americana que atuava no beneficiamento e processamento de carnes, com base no modelo taylorista de produção, encontrou em Rio Grande concessões dadas pelo governo estadual e municipal para a sua instalação, como a isenção das taxas de exportação de matéria prima. (MARTINS, 2006)

Com a Segunda Guerra Mundial (1939-1945) as indústrias instaladas em Rio Grande mantiveram um elevado índice de produção, possibilitado pela capacidade de escoar a sua produção via porto. Porém, as crises mundiais, principalmente pela estreita relação com o comércio europeu, contribuíram para a falência de muitas indústrias locais e o fim das atividades de algumas delas no século XX (CESAR, 2015). Dentre alguns dos fatores que contribuíram para a decadência das indústrias locais no cenário nacional está a defasagem tecnológica, em relação à produção paulista e a concorrência dos produtos fabricados na serra gaúcha, porém o porto manteve-se importante escoando a produção do estado.

Nos anos de 1950 a 1970 ocorreu à estagnação do parque industrial local, recuperando-se parcialmente a partir do desenvolvimento da indústria pesqueira, impulsionada pelo financiamento pelo governo federal para o setor pesqueiro (MARTINS, 2006). Entretanto, esse setor não refletiu nas atividades portuárias, mas na instalação de um conjunto de fábricas de processamento de pescado e na formação de uma frota de barcos pesqueiros de grande porte. Porém, com o fim dos incentivos fiscais para a produção pesqueira, baseada na redução do papel do estado na economia, e a diminuição da oferta de matéria prima ocasionou o declínio da atividade pesqueira em Rio Grande. (RENNER, 2012)

Durante a ditadura civil-militar (1964-1985), o município do Rio Grande foi definido como Área de Segurança Nacional, condição estabelecida pela política praticada pelos militares no comando do país, em que as capitais estaduais e cidades estratégicas, com importância para a segurança e o desenvolvido econômico nacional, passaram a ser administradas por interventores. A formação de um planejamento estratégico voltado para o desenvolvimento do estado do Rio Grande do Sul passava pelo porto. "O porto de Rio Grande foi um dos que mais investimentos recebeu do governo federal tanto nos anos setenta como nos anos oitenta" (DOMINGUES, 1995, p. 8-9). Investimentos que não estavam voltados exclusivamente para o porto, mas também para toda a infraestrutura necessária para o pleno funcionamento da logística, como nas rodovias de ligação ao porto.

Como nó estratégico, na década de 1970, o porto de Rio Grande recebeu significativos investimentos oriundos do Estado com objetivo de transforma-lo em um corredor de exportação para a produção do sul do país iniciando em 1972 a construção do SuperPorto, juntamente com as melhorias no canal de acesso, na armazenagem, na estocagem e na ampliação e modernização dos terminais portuários. Na construção do Superporto, do Distrito industrial (área próximo a zona

ParaOnde!?, Porto Alegre, v.11, n.1, p.45-54, 2019. http://seer.ufrgs.br/paraonde

Edição Especial: "Geografia e transformações socioespaciais: dinâmicas agrárias e políticas do desenvolvimento regional" 
portuária destinada à instalação industrial), e no Corredor de Exportação do estado foram investidos mais de quatro bilhões de dólares.

A construção das novas estruturas portuárias foi financiada com recursos públicos, com objetivo de atender as novas demandas. 0 capital privado foi direcionado à implantação de indústrias de fertilizantes e óleos vegetais e em armazéns e silos. Os investimentos em rodovias, ferrovias, energia elétrica, telecomunicação e abastecimento de água, voltados ao complexo portuário e para o distrito industrial totalizaram mais de três milhões de dólares. (DOMINGUES, 1995)

Com a abertura ao capital privado foram instaladas no município indústrias de fertilizantes e óleo vegetal, relacionadas ao desenvolvimento agrícola do estado e o porto torna-se fundamental para economia gaúcha. (MARTINS, 2006). 0 projeto político e econômico, embasado na Revolução Verde, atraiu grupos multinacionais que forneciam insumos agrícolas. A modernização da agricultura e o aumento da monocultura, voltado ao mercado externo, elevaram a dependência às conexões marítimas. As indústrias de bens intermediários aproveitaram o porto para seu desenvolvimento, uma vez que os componentes químicos, dos fertilizantes, são importados e a soja e seus derivados são exportados, via porto do Rio Grande.

Terminais de Uso Privado foram instalados no distrito industrial, destinados à movimentação de petroquímicos, fertilizantes, granéis agrícolas e contêineres nas décadas de 1970 e 1980 . Assim Rio Grande consolidou-se como um importante nó na complexa rede global. Contudo, no inicio da década de 1990, uma série de medidas fiscais baseadas no Consenso de Washington (1989) e políticas econômicas neoliberais forçaram os processos de privatizações e abertura do mercado nacional, situações essas que afetaram diretamente Rio Grande, e principalmente a movimentação portuária. (MARTINS, 2013)

A privatização de terminais portuários, baseada na Lei de modernização dos Portos de 1993, iniciou no Brasil uma restruturação portuária. Em Rio Grande a implantação de terminais privados destinados a grãos e contêineres, ocasionou uma mudança no perfil das exportações nos anos 1990. 0 salto no volume de movimentação de cargas, crescente a cada ano, levou a uma separação entre o crescimento do porto e o desenvolvimento do município, fruto do novo modelo portuário mais acelerado. Nesse período o papel do Estado é de um facilitador das relações econômicas, investindo em infraestrutura para a qualificação do território.

Após 2000 as políticas de incentivo à produção nacional de navios e similares deram uma nova funcionalidade à zona portuária do Rio Grande. A partir de 2002, com o investimento de recursos estatais na construção de plataformas de petróleo pela indústria nacional, as atividades portuárias e navais surgiram como opção para área portuária. Carvalho (2001) coloca a ação do governo como reflexo da pressão do setor de construção naval, como o Sindicato Nacional de Construção e Reparação Naval e Offshore (SINAVAL), empresários do estado do Rio de Janeiro, que concentra as indústrias do setor. Somam-se a isso: o alto custo da renovação da frota da PETROBRAS, a descoberta do pré-sal e a mudança na política de licitações da Agência Nacional do Petróleo, Gás Natural e Biocombustíveis (ANP).

A necessidade de estaleiros com maior capacidade física e as condições do calado (profundidade do canal) fez com que o sítio portuário de Rio Grande fosse uma opção para a ampliação naval no país (DOMINGUES e CARVALHO, 2009). Com isso, dá-se início à instalação de um complexo naval no município, movimentando a economia não apenas local, mas sim de todo o estado do Rio Grande do Sul, demonstrando mais uma vez a capacidade regional do porto local. A política nacional de descentralização do setor naval atraiu um novo conjunto de atores que alteraram a organização do território e das relações sociais, políticas e econômicas.

\section{Considerações Finais}

A função e a capacidade dos atores territoriais não são permanentes, o seu papel pode variar a partir das demandas de cada período e refletir nas transformações territoriais. 0 Estado é um significativo exemplo de ator que modificou suas ações e funções mediante as diferentes situações e

ParaOnde!?, Porto Alegre, v.11, n.1, p.45-54, 2019. http://seer.ufrgs.br/paraonde

Edição Especial: "Geografia e transformações socioespaciais: dinâmicas agrárias e políticas do desenvolvimento regional” 
interesses da conjuntura territorial, podendo em alguns momentos impor seus anseios ou apenas agir como um agente mediador para as ações de outros atores.

Com as mudanças nas relações econômicas, políticas e sociais surgem novos atores territoriais. Os agentes econômicos, os sindicatos e os partidos políticos são exemplos de novos atores que possuem a capacidade de influenciar na transformação do território. A construção de uma rede global conectada é consequência da organização dos atores e das formas elaboradas de usar o território. A cada novo momento além das novas relações são necessárias novas estruturas para suportar os diferentes usos do território.

E a formação de um nó estratégico, como o porto do Rio Grande, é cenário para a atuação de distintos atores e reflexo da conexão territorial global. As transformações ocorridas na zona portuária são decorrentes das mudanças das relações econômicas, políticas e sociais, as quais ocorrem a partir da ação de atores. A construção de estruturas portuárias e retro portuárias, com capacidade de suportar a movimentação de diferentes cargas em menor tempo, são marcas das distintas composições de atores que explora esse nó territorial.

Os interesses sobre o território são alterados mediante as transformações das relações e do papel dos atores territoriais. As ações de cada ator refletem e são reflexos das necessidades de cada momento e das condições impostas ao território. A então vila do Rio Grande passou de um ponto de demarcação territorial, para um nó estratégico para o desenvolvimento econômico do estado do Rio Grande do Sul. A chegada de comerciantes ainda no século XVII e a instalação de terminais privados na década de 1990, são alguns exemplos de atores que ao se inserirem no território portuário obrigaram a uma reorganização territorial.

Compreendendo a construção de um porto sem reconhecer a atuação dos atores é simplesmente incoerente, devido à capacidade de reestruturar o território a partir da ação dos mesmos. Entre os atores envolvidos na configuração do nó estratégico o Estado possui um papel singular perante os demais atores, pois mesmo que suas funções tenham sido alteradas, a partir de novas conjunturas, a sua atuação é fundamental para o desenvolvimento territorial.

\section{Referências}

BITTENCOURT, Ezio. Da Rua ao teatro: os prazeres de uma cidade. Rio Grande: sociabilidades e cultura no Brasil Meridional (Panorama da história de Rio Grande). Rio Grande: Editora FURG, 2001.

CARVALHO, Andréa Bento. Polo Naval do Rio Grande: desafio a estruturação técno-produtiva do território. Dissertação (Mestrado em Geografia) - Programa de Pós-Graduação em Geografia, Instituto de Ciências Humanas e da Informação, Universidade Federal do Rio Grande, Rio Grande, 2011.

DOMINGUES, Marcelo Vinicius de La Rocha. Superporto de Rio Grande: plano e realidade elementos para uma discussão. Dissertação (Mestrado em Ciências) - Instituto de Geociências, Universidade Federal do Rio de Janeiro, Rio de Janeiro, 1995.

DOMINGUES, Marcelo Vinicius de la Rocha; CARVALHO, Diogo Sá. A evolução do comércio marítimo internacional e seus reflexos na industria naval mundial. In: DOMINGUES, Marcelo Vinicius de la Rocha (Coord.). Desenvolvimento e consolidação do polo naval e offshore de Rio Grande. Rio Grande: FURG, 2009. p. 21-58.

FONT, Nogué Joan; RUFÍ, Joan Vicente. Geopolítica, identidade e globalização. São Paulo: Annablume, 2006.

HARVEY, David. A produção capitalista do espaço. São Paulo: Annablume, 2005.

MARTINS, César Augusto Ávila. Desenvolvimento e direito à cidade. In: MULLER, Cristiano; MOROSO, Karla. (Orgs.) Violações ao direito à cidade e à moradia decorrentes de megaprojetos de desenvolvimento no Rio Grande do Sul: diagnostico e perspectivas: o caso de Rio Grande. 1.ed. Porto Alegre: Centro de Direitos Econômicos e Sociais, 2013. p. 37-39.

ParaOnde!?, Porto Alegre, v.11, n.1, p.45-54, 2019. http://seer.ufrgs.br/paraonde

Edição Especial: "Geografia e transformações socioespaciais: dinâmicas agrárias e políticas do desenvolvimento regional” 
MARTINS, Solismar Fraga. Cidade do Rio Grande: industrialização e urbanidade (1873-1990). Rio Grande: Editora da FURG, 2006.

MARTINS, Solismar Fraga: PIMENTA, Margareth Afeche. A constituição espacial de uma cidade portuária através dos ciclos produtivos industriais - 0 caso do município de Rio Grande. Revista Brasileira de Estudos Urbanos e Regionais, Rio de Janeiro, v.6, n.1, 2004. p. 85-100.

PESAVENTO, Sandra Jatahy. História da Indústria Sul-Rio-Grandense. Rio Grande Companhia de Celulose do Sul (Riocell). Guaíba, 1985

PRADEL, Antonio. Histórico da Barra do Rio Grande: comemorando os 135 anos de fundação da Câmara do Comércio. 1979.

RAFFESTIN, Claude. Por uma geografia do poder. São Paulo: Ática, 1993.

RAMOS, Simone da Mata. A importância dos Molhes da Barra do Rio Grande no contexto da economia do Rio Grande do Sul. In: Alves, Francisco das Neves (ORG). Cidade do Rio Grande: ensaios históricos. Rio Grande: Editora FURG, 2002. p. 47-80.

RENNER, Marco Antônio da Gama. As transformações na organização da industrialização de pescado em Rio Grande - RS. Dissertação (Mestrado em Geografia) do Programa de Pós-Graduação em Geografia, Instituto de Ciências Humanas e da informação, Universidade Federal do Rio Grande, Rio Grande, 2012.

RÜCKERT, Aldomar A. Reforma do Estado e tendências de reestruturação territorial. Cenários contemporâneos no Rio Grande do Sul. 2001. 662 f. Tese (Doutorado) - FFLCH, Programa de PósGraduação em Geografia Humana, Universidade de São Paulo. São Paulo, 2001.

. A estrutura territorial do estado do Rio Grande do Sul - Gênese e Construção. In: Boletim gaúcho de Geografia. Vol. 29, $\mathrm{n}$ 1, 2003. Disponivel em: https://seer.ufrgs.br/bgg/article/view/38740/26250. Acessado em 25/03/2019.

ROSIÈRE, Stephan. Les acteurs géopolitiques. Géographie politique \& Géopolitique. 2e édition. Paris: Ellipses Édition. 2007.

SALVATORI, Elena; HABIAGA, Lydia Angélica Gómez de Perez; THORMANN, Maria do Carmo. Crescimento horizontal da cidade do Rio Grande. Revista Brasileira de Geografia, Rio de Janeiro, v.51, n.1, p. 27-71, jan./mai. 1989.

SANTOS, Milton; SILVEIRA, Maria Laura O Brasil: território e sociedade no início do século XXI. São Paulo, Editora Record, 2001.

SECRETARIA DA SEGURANÇA PÚBLICA DO RIO GRANDE DO SUL. Desempenho do Complexo Portuário Brasileiro em 2013 (2014). Disponível em: http://www.portosdobrasil.gov.br/home1 /estatisticas/desempenho-do-complexo-portuario-brasileiro-em-2013. Acesso em 08/11/2016.

SCHERER, M.E.G.; SANCHES, M.; NEGREIROS, D.H. Gestão das Zonas Costeiras e as Políticas Públicas no Brasil: um diagnóstico. In: Juan Manuel Barragan Muñoz (Coord.), Manejo Costero Integrado y Política Pública en Iberoamérica: Un diagnóstic. Necesidad de Cambio, pp. 291-330 , Red Ibermar (CYTED), Cádiz, Espanha, 2009. ISBN: 978-8469303559. Disponível em: http://hum117.uca.es/HUM117/ibermar/Resultados\%20y\%20descargas/publicaciones/brasil; Acesso em 12/11/2016

TAYLOR, Peter J.; FLINT, Colin. Geografía política; economía-mundo, Estado-Nación y localidad. $2^{\text {a }}$ ed. Madrid: Trama Editorial, 2002.

WILLY, Cesar. A cidade do Rio Grande: do big bang a 2015. Rio de Janeiro: Topbooks, 2015.

ParaOnde!?, Porto Alegre, v.11, n.1, p.45-54, 2019. http://seer.ufrgs.br/paraonde 